\section{Früherkennung per Mikro-RNA}

\begin{abstract}
Zirkulierende tumorspezifische Mikro-RNA (miRNA) im Plasma könnte eine einfache, minimalinvasive Methode zur Brustkrebs-Früherkennung sein. Das Deutsche Krebsforschungszentrum suchte nach aussichtsreichen Kandidaten.
\end{abstract}

$\mathrm{M}$ ikro-RNA besteht aus $18-25 \mathrm{Nu}-$ kleotiden und reguliert die Prozessierung der RNA nach der Transkription. Zirkulierende miRNAs haben in den letzten Jahren als neue Marker für verschiedene Erkrankungen viel Aufmerksamkeit erhalten. Um zu prüfen, ob sie auch für eine Brustkrebs-Früherkennung infrage kommen, verglichen die Heidelberger Forscher zunächst Blutproben von zehn Patientinnen mit frühem invasivem duktalem Mammakarzinom des Stadiums I und II (ER/PR+ und HER2-) und zehn gesunden Kontrollen, um Kandidaten für Brustkrebs-Biomarker zu finden. Von 16 bei Patientinnen und Kontrollen signifikant unterschiedlich exprimierten miRNAs waren sechs bei einem Mammakarzinom hoch- und zehn herunterreguliert. Die sieben aussichtsreichsten Kandidaten validierten die Untersucher dann in einer Kohorte von insgesamt 127 Brustkrebspatientinnen und 80 gesunden Kontrollen. Danach waren im Plasma der Mammakar-

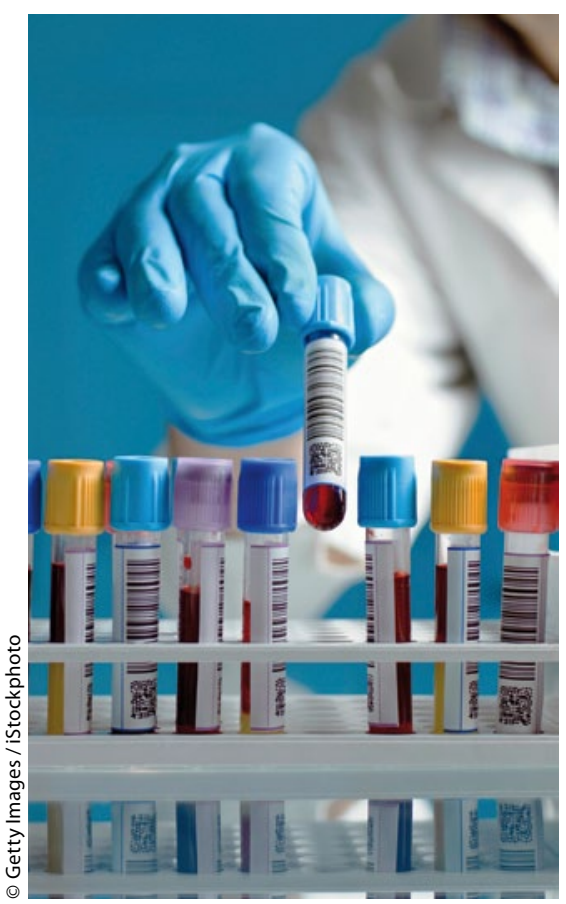

Forscher suchten nach geeigneten Brustkrebs-Biomarkern. zinompatientinnen vier miRNAs signifikant gegenüber den Kontrollen hochreguliert: miR-148b, miR-376c, miR-409$3 \mathrm{p}$ und miR-801. Interessanterweise waren andererseits miR-148b, miR-376c und miR-409-3p im Tumorgewebe herunterreguliert - bis heute ist der Ursprung der zirkulierenden miRNAs unklar und wie sie in die Blutbahn gelangen.

Die ROC-Kurvenanalyse zeigte, dass die Kombination der drei Marker miR148b, miR-409-3p und miR-801 eine ebenso gute Trennschärfe ermöglichte wie die Analyse aller vier Biomarker (Area under the Curve, AUC = 0,69). Bei einer $70 \%$ igen Sensitivität ergab sich eine mediane Spezifität von $55 \%$ - für eine Früherkennungsuntersuchung also alleine bei weitem nicht ausreichend.

Fazit: Die identifizierten Biomarker könnten für die Entwicklung eines Blutbasierten, viele weitere Marker einbeziehenden Tests hilfreich sein, der dem Screening vorangestellt werden könnte. Er könnte dann die Entscheidung unterstützen, wann eine weitere Diagnostik sinnvoll sein könnte. Friederike Klein

Cuk K et al. Circulating microRNAs in plasma as early detection markers for breast cancer. Int J Cancer. 2013;132(7):1602-12.

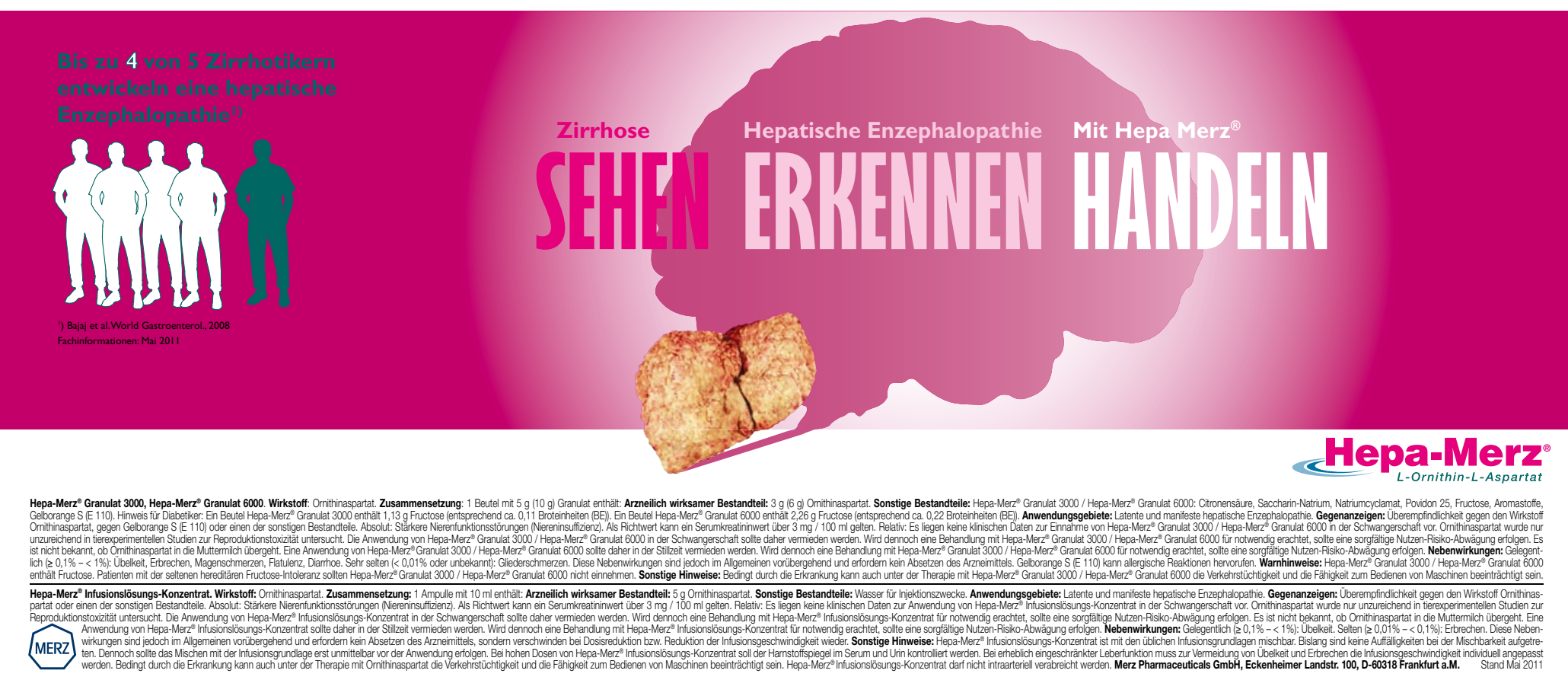

